\title{
Medical and pharmacological approach to adjust the salbutamol anti-doping policy in athletes
}

Fabien Pillard ${ }^{1,2,3^{*}}$, Michel Lavit ${ }^{4}$, Valérie Lauwers Cances ${ }^{5}$, Jacques Rami ${ }^{1}$, Georges Houin ${ }^{4}$, Alain Didier ${ }^{6}$ and Daniel Rivière ${ }^{1,2,3}$

\begin{abstract}
Background: Salbutamol abuse detection by athletes is based on a urinary upper threshold defined by the World Anti-Doping Agency (WADA). However, this threshold was determined in healthy, untrained individuals and after a dose of salbutamol inhaled that might not really mirror the condition of asthmatic athletes and the experts's guidelines for asthma management. We aimed to revise this threshold in accordance with recommended clinical practice (that appear to be different from the actual WADA recommendation) and in exercise conditions.

Methods: For the present open-label design study, we included 12 trained male cyclists (20 to $40 \mathrm{y} / \mathrm{o}$ ) with asthma. Differently from the previous pharmacokinetic study supporting the actual salbutamol urinary upper threshold, we decided to administer a close to recommended clinical practice daily dose of $3 \times 200 \mu \mathrm{g} . \mathrm{d}^{-1}$ inhaled salbutamol (instead of $1600 \mu \mathrm{g} . \mathrm{d}^{-1}$ as authorized by the anti-doping policy). Urine salbutamol concentration was quantified by liquid chromatography-tandem ion trap mass spectrometry and corrected for urine density, at rest and after a 90-min cycling effort at 70-80 \% of the maximal aerobic power.

Results: The maximum urine salbutamol concentration value peaked after the cycling effort and was $510 \mathrm{ng} \cdot \mathrm{mL}^{-1}$. That is twice lower than the actual WADA threshold to sanction salbutamol abuse, this "legal" threshold being based on pharmacokinetic data after a daily dose that is 8 fold the total dose sequentially administrated in our study. Considering its $95 \%$ confidence interval, this threshold value could be more stringent.

Conclusion: By using conditions in accordance with the experts' clinical and safety guidelines for asthma management in athletes undergoing an intense exercise bout, our study suggests that the urine salbutamol concentration threshold could be lowered to redefine the rule supporting the decision to sanction an athlete for salbutamol abuse.
\end{abstract}

Keywords: Salbutamol, Sport, Doping, Beta2 agonist, Control

\section{Background}

Although the efficacy of anti-doping controls has improved, fighting against doping remains a priority in sport policy. As exposed in the Final Revised 2015 World Anti-Doping Code edited by the World AntiDoping Agency (WADA), prevention (ethic and health

\footnotetext{
* Correspondence: pillard.f@chu-toulouse.fr

${ }^{1}$ Respiratory Function Exploration and Sport Medicine Department, Larrey Hospital, 24 Chemin de Pouvourville, TSA 30030, 31059 Toulouse Cedex 9, France

${ }^{2}$ Exercise Physiology Department, Medical School, Paul Sabatier University,

Toulouse, France

Full list of author information is available at the end of the article
}

public aspects), detection (doping control) and sanction are key aspects of anti-doping policies [1].

The WADA list [1] of prohibited substances is accepted worldwide and has been adopted by the International Olympic Committee (IOC). For instance, beta2-adrenergic receptor agonist (BA) are listed as banned substances because they can be used for athletic performance enhancement [2-4]. However, BA are listed as one the medications to prevent and treat the symptoms of exercise-induced bronchospasm (EIB) among athletes, with or without a known diagnosis of asthma. Accordingly, athletes are sanctioned for BA use except when 
taking salbutamol, salmeterol and formoterol, for medical reasons, by inhalation, at a maximum dose and the urine concentration must not exceed a threshold value for salbutamol and formoterol.

Salbutamol is one of the most popular short-acting BA (SABA) used to relieve asthma symptoms. This medication can prevent asthma symptoms and should be taken 10 to $15 \mathrm{~min}$ before exercise. It will help prevent symptoms for up to four hours. Salbutamol can also be used to treat and reverse the symptoms of EIB. Based on the current WADA guidelines, the SABA salbutamol can be prescribed up to $1600 \mu \mathrm{g}$ per $24 \mathrm{~h}$. According to recent expert clinical guidelines from Global Initiative for Asthma (GINA) recommendations [5] and the American Thoracic Society (ATS) Clinical practice guidelines [6], SABAs can be prescribed during sport practice to prevent EIB, just before exercise: inhaled doses of 200-400 $\mu \mathrm{g}$ could be inhaled just before exercise as suggested by Tan et al. [7]. In addition, doses between 400 to $800 \mu \mathrm{g}$ can be inhaled up to the 2nd or 4th hour of asthma attack, and then repeated if necessary but this situation should be considered with caution among athletes because acute and intense exercise triggers EIB [8]. Anyway, inhalation of $1600 \mu \mathrm{g}$ is neither encouraged in a day for prevention of EIB. To justify the WADA daily upper limit of $1600 \mu \mathrm{g} . \mathrm{d}^{-1}$ for inhaled salbutamol (a limit that is 2.5 fold higher than the limit proposed by experts in asthma), Dickinson et al. suggested that this limit was proposed by WADA to take into account the fact "that asthmatic athletes are often instructed to use their inhaler on an as needed basis that could be interpreted by the athletes as a clearance to inhale unlimited amounts of salbutamol to combat respiratory symptoms" [9]. However, this assertion is in contradiction with experts guidelines cited above (GINA and ATS recommendations) and with recommendations published in a very recent review published by Boulet et al. [10]. According to these guidelines and recommendations, SABAs should be used only as-needed at the lowest dose and frequency required to prevent eventual tachyphylaxis. Moreover, this assertion could be discussed based on clinical practice and ethical considerations. Indeed asthma requiring such high BA doses should not be compatible with current high level physical and sports performance if we consider that the high levels of ventilation sustained in such exercise conditions are identified as triggers for EIB [2].

A second question concerns the maximum urine concentration of salbutamol accepted in the case of "therapeutic prescription". Historically, salbutamol was the first bronchodilatator listed in the international anti-doping list according to a urinary threshold for sanction. According to Dickinson [9], this current WADA urinary threshold (1000 ng.mL ${ }^{-1}$ ) is based on data published in 2000 by Berges et al. [11]. In this study, non-asthmatic recreational swimmers inhaled $1600 \mu \mathrm{g}$ salbutamol and then the urine salbutamol concentration was determined at rest. This study, like all the other studies consecutively published with the objective of assessing salbutamol pharmacokinetics after inhalation or oral administration (Table 1), was not conducted in asthmatic competitive athletes and samples were not collected during exercise. Therefore, it can be concluded that no study was conducted in laboratory conditions mirroring the exercise conditions experienced by asthmatic athletes. In addition, none of the studies on salbutamol was performed using an adjusted and clinical relevant dose of salbutamol to manage asthma or EIB in athletes (i.e., a dosing regimen in accordance with experts' recommendations in the field).

Accordingly, the objective of our study was to assess the pharmacokinetics of inhaled salbutamol 1) in asthmatic athletes and 2) after a single bout of intense exercise and 3) after a recommended (by experts in asthma but not according to the WADA list) dosing regimen of inhaled salbutamol for athletes undergoing an intense exercise bout (i.e. $200 \mu . \mathrm{d}^{-1}$ of salbutamol three times per day).

\section{Methods \\ Study design}

This study used an open-label design. All participants visited our laboratory four times. During the first visit the diagnosis of asthma was confirmed by direct bronchial provocation test with methacholine chloride. During the second visit, the endurance capacity was assessed to determine the intensity of the exercise session. Then, two consecutive sessions were dedicated to assessing salbutamol pharmacokinetics in plasma and urine at rest (rest pharmacokinetic session, D1) and, the next day, during a bout of intense endurance exercise (exercise pharmacokinetic session, D2). Participants were asked to stop their current anti-asthmatic treatment three days before the rest pharmacokinetic session and to inhale salbutamol three times per day (see the Medications section; study design is presented in Fig. 1).

The study protocol was approved by the scientific committee of the French Anti-Doping Agency and by the Toulouse hospital ethics committee (agreement $n^{\circ}$ 0830103).

\section{Participants and lung function assessment}

This study included 12 men, aged between 20 and 40 year. They were trained cyclists and were enrolled in the study if they practiced eight hours or more of cycling per week. All were enrolled in competition. All were non smokers. All experienced clinical symptoms of asthma according to GINA classification, including EIB and all had been using a SABA on demand for at least one year. All the patients used SABA at least one time during the two weeks before their enrollment in the study. 
Table 1 Published studies on the pharmacokinetics of inhaled salbutamol (updated on the 31st July 2014)

\begin{tabular}{|c|c|c|c|c|c|c|}
\hline & Physical activity & Asthmatic status & Salbutamol inhaled dose & Rest or exercise & Exercise intensity & Sample size \\
\hline Anderson1998 [26] & Untrained & Healthy & $1 \times 180 \mu \mathrm{g}$ & Rest & & 10 \\
\hline \multirow[t]{2}{*}{ Berges2000 [11] } & \multirow[t]{2}{*}{ Trained } & Asthmatic & $1 \times 200 \mu \mathrm{g}$ & \multirow[t]{2}{*}{ Rest } & & 15 \\
\hline & & Healthy & $4 \times 400 \mu \mathrm{g}$ & & & 17 \\
\hline Pichon2006 [27] & Trained & Healthy & $3 \times 200 \mu \mathrm{g}$ & Rest & & 10 \\
\hline \multirow[t]{3}{*}{ Sporer2008 (1) [28] } & \multirow[t]{3}{*}{ Trained } & \multirow[t]{3}{*}{ Healthy } & $1 \times 200 \mu \mathrm{g}$ & \multirow{3}{*}{$\begin{array}{l}\text { Exercise } \\
\text { (and Rest) }\end{array}$} & \multirow[t]{7}{*}{ Cycling time } & 30 \\
\hline & & & and $1 \times 400 \mu \mathrm{g}$ & & & \\
\hline & & & and $1 \times 800 \mu \mathrm{g}$ & & & \\
\hline Sporer2008 (2) [29] & Untrained & Healthy & $1 \times 200 \mu \mathrm{g}$ & Rest & & 8 \\
\hline Elers2010 [30] & Untrained & Asthmatic & $1 \times 200 \mu \mathrm{g}$ & Rest & & 10 \\
\hline \multirow[t]{2}{*}{ Elers2011 [31] } & \multirow[t]{2}{*}{ Untrained } & Asthmatic & \multirow[t]{2}{*}{$4 \times 400 \mu \mathrm{g}$} & \multirow[t]{2}{*}{ Rest } & & 10 \\
\hline & & Healthy & & & & 10 \\
\hline \multirow[t]{2}{*}{ Elers2012 [19] } & \multirow[t]{2}{*}{ Trained } & Asthmatic & $1 \times 800 \mu \mathrm{g}$ & \multirow[t]{2}{*}{ Rest } & & 10 \\
\hline & & Healthy & & & & \\
\hline \multirow[t]{2}{*}{ Dickinson2014 [9] } & \multirow[t]{2}{*}{ Trained } & \multirow[t]{2}{*}{ Healthy } & $1 \times 800 \mu \mathrm{g}$ & \multirow{2}{*}{$\begin{array}{l}\text { Exercise } \\
\text { (and Rest) }\end{array}$} & \multirow{2}{*}{$\begin{array}{l}\text { Not } \\
\text { specified }\end{array}$} & \multirow[t]{2}{*}{32} \\
\hline & & & and $1 \times 1600 \mu \mathrm{g}$ & & & \\
\hline Theoretical "Link-field study" & Trained & Asthmatic & $\begin{array}{l}\text { Preventive } \\
\text { dose: } 3 \times 200 \mu \mathrm{g}\end{array}$ & $\begin{array}{l}\text { Exercise } \\
\text { (and Rest) }\end{array}$ & Exercise & Powerful \\
\hline
\end{tabular}

Bold data identify conditions that we consider as optimal based on a rigorous clinical and scientific approach

Patients reported they used SABA some days before exercise when they observed a "short breath" compared to other days. No one had ever had a severe asthma attack. In the absence of exacerbations, our cohort was defined as a mild asthma cohort.

Only men were studied in this preliminary study to exclude any pharmacological variation related to menstrual hormonal disturbances in women.

Written informed consent was obtained by all subjects.
The methacholine challenge test was used to confirm the diagnosis of asthma and a negative challenge test was used to exclude the diagnosis of asthma. All the participants were asked to stop their SABA at least $48 \mathrm{~h}$ before lung function assessment [12]. Pulmonary function testing was done using a whole body plethysmograph (Jaeger Master Screen Body ${ }^{\mathrm{ma}}$ Plethysmograph). The methacholine challenge test was performed using the aerosol provocation system (APS) dosimeter technique

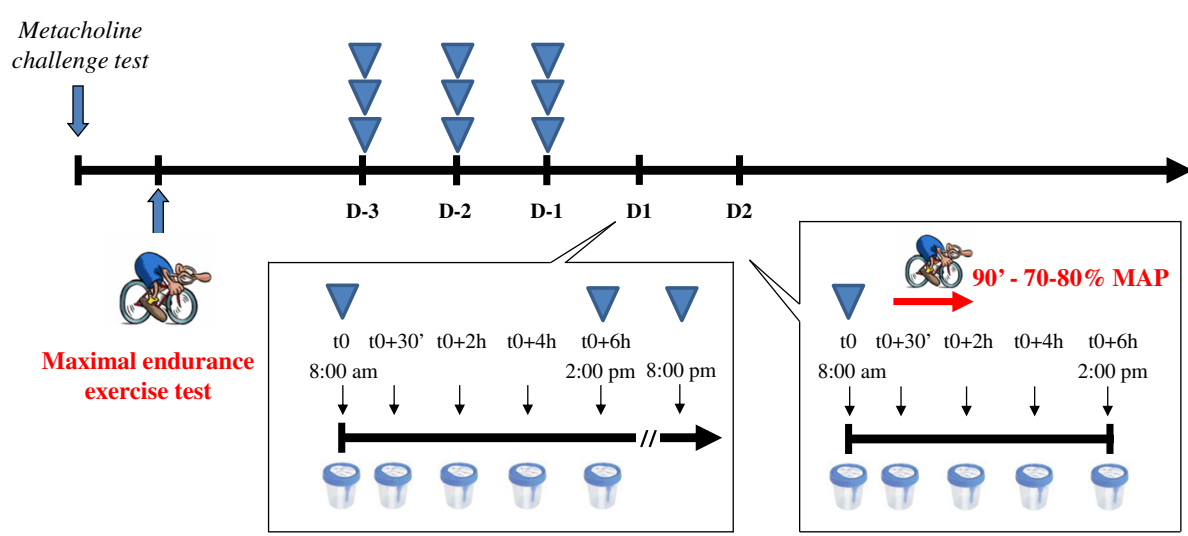

Legends

Urine sample

$200 \mu \mathrm{g}$ Salbutamol inhalation (8:00 am, 2:00 pm and 8:00 pm)

Fig. 1 Study design 
(APS, Viasys) [13]. The cumulative dose of methacholine provoking a $20 \%$ decrease (PD20) in the forced expiratory volume in $1 \mathrm{~s}$ (FEV1) was calculated to confirm the participant's asthmatic status. According to the ATS guidelines, the PD20 threshold was set at $1600 \mu \mathrm{g}[12,13]$.

\section{Endurance exercise testing and endurance exercise during the exercise pharmacokinetic session}

The participant's endurance capacity was assessed to check their fitness level. To this aim, maximal graded exercise tests were conducted in our laboratory. Subjects used their own bicycle and equipment. The power output was assessed using the Power Tap mobile cycling ergometer $^{\circledR}$ (Cycle Ops, Madison, WI, USA) [14]. During the test, oxygen consumption $\left(\mathrm{VO}_{2}\right.$, expressed in L.min ${ }^{-1}$ and $\mathrm{mL} \cdot \mathrm{min}^{-1} \cdot \mathrm{kg}^{-1}$ ) was assessed using an Oxycon Pro ergospirometer $^{\ominus}$ (Erich Jaeger, Viasys Healthcare, Germany). The $\mathrm{VO}_{2}$ max and its corresponding power, the maximal aerobic power (MAP) were measured.

During the exercise pharmacokinetic session, subjects performed a $90 \mathrm{~min}$ bout of endurance exercise in the same general conditions as for the MAP determination (i.e., on their own bicycle and power output was assessed by using the Cycle OPS Power Tap ${ }^{\mathrm{TM}}$ system). After 10-min warm up at $60 \%$ of their MAP, participants were asked to exercise at $70-80 \%$ of their MAP for the last $80 \mathrm{~min}$.

\section{Medications}

At enrolment, all participants declared salbutamol use on demand $\left(2 \times 100 \mu \mathrm{g}\right.$. $\mathrm{d}^{-1}$ just before exercise or in case of asthma symptoms). None of them reported salbutamol dose higher than $400 \mu \mathrm{g} . \mathrm{d}^{-1}$ over the past year before enrolment in this study. Four declared a treatment to control asthma (see Subjects in the Results section). All subjects had to abstain from using any medicine, including SABA, 2 weeks before the pharmacokinetic session.

The protocol of the study is detailed in Fig. 1. At least one week before the rest pharmacokinetic session (D1, Fig. 1), all participants received a full salbutamol aerosol inhaler and a valve holding chamber. To follow salbutamol consumption, the weight of two puffs was arbitrarily defined by weighing each inhaler before and after 4 puffs and the weigh difference divided by two.

Each participant received written and oral instructions to inhale salbutamol three times a day (2 puffs/each time). Participants were asked to inhale $200 \mu \mathrm{g}$ salbutamol three times daily scheduled for 3 consecutive days (D1-3, D1-2, D1-1). This scheme of salbutamol inhalation was reproduced on the 4th consecutive day designed as the rest pharmacokinetic session (D1). From D1-3 to D2 (exercise pharmacokinetic session, next day after D1), salbutamol was administered in the same conditions. Participants were asked to bring back the inhaler at D2. At the end of the exercise pharmacokinetic session, the inhaler was weighted again and the difference in weight was used to control salbutamol administration.

Despite subjects enrolled in the study were not under a daily salbutamol inhalation treatment scheme, regular and pre-exercise inhalation of salbutamol were proposed for the study to mimic a treatment scheme by SABA that might be proposed as a part of the global treatment (SABA and addition of a controller) for more severe asthmatics. The dose of $200 \mu \mathrm{g}$ for each of the three daily inhalations was defined because this dose is close to the maximal dose recommended before exercise $(400 \mu \mathrm{g})$ while this dose would be usual for mild asthmatic subjects.

\section{Urine sample}

During the rest and exercise pharmacokinetic sessions, urine was collected at baseline $\left(T_{O}\right)$ and at $30 \mathrm{~min}, 2 \mathrm{~h}$ (i.e., just after the 90-min intense exercise in the case of the exercise pharmacokinetic session), $4 \mathrm{~h}$ and $6 \mathrm{~h}$ after the first dose of $200 \mu \mathrm{g}$ of salbutamol. Participants were encouraged to drink water regularly to favour urine excretion for sampling. Night urine was collected at home by the participants in a dark container and delivered to our laboratory kept out from light. For each time point, the total urine sample volume was recorded and two $30 \mathrm{~mL}$ aliquots were stored at $-80{ }^{\circ} \mathrm{C}$ until analysis.

\section{Bioanalytical analysis of urine samples}

Urine samples were pre-treated according to the current procedures used by anti-doping laboratories to detect total salbutamol (i.e., salbutamol and its glucuronide) [15]. Salbutamol-D9 was used as internal standard. After extraction from urine by solid-phase extraction, salbutamol concentration was assessed by hydrophilic interaction chromatographic and liquid chromatography with atmospheric pressure chemical ionization mass spectrometry. Bioanalytical analyses were performed at the Pharmacokinetic and Toxicological Laboratory of Toulouse Hospital (France). This laboratory is accredited by COFRAC, the French accreditation body, under the European norm $n^{\circ} 1589$.

Urine salbutamol concentration values were corrected to the urine density, as previously recommended [9]. The maximum urine concentration of salbutamol for each participant and for each experimental session was defined as the highest value for each session $\left(\mathrm{C}_{\mathrm{u}}\right.$ max-rest and $\mathrm{C}_{\mathrm{u}}$ max-ex, in ng.mL ${ }^{-1}$, were labeled for resting and exercising session respectively). For each participant, the highest of these values was defined as the $C_{u}$ max (the maximum urine concentration of salbutamol that could 
be detected for each participant, regardless the specific rest or post-exercise conditions).

\section{Statistical analysis}

Sample size calculation to fit well-powered analysis in order to test our main hypothesis was based on the salbutamol concentration distribution in urine samples described by Tomlinson et al. [16] and with the aim of computing the confidence interval for salbutamol concentration in urine according to the general methodological recommendations by Gardner and Altman [17] and the recommendations edited by an Expert Panel on Theory of Reference Values from the International Federation of Clinical Chemistry and Laboratory Medicine [18]. We thus needed to include 12 subjects to assume a precision of 85 and a $95 \%$ confidence level for the confidence interval. The confidence intervals of salbutamol distribution were computed for 95 and $99 \%$ confidence levels.

For bivariate analysis, the normality of distribution of quantitative variables was tested using the skewness and kurtosis test (sktest). As some variables differed from the normal distribution, bivariate analysis was performed using the Wilcoxon matched-pairs ranks test or the Friedman's test for repeated variables. Bivariate analysis was carried out with a significance level $<0 \cdot 05$. For repeated variables, a Bonferroni adjustment of this significance level was performed to conclude on the significance of the corresponding multiple comparisons (corresponding to multiple time points).

All statistical analyses were performed with the Stata $6 \cdot 0$ software (Stata Corporation, College Station, TX).

\section{Results}

\section{Subjects}

Twelve subjects (mean age: 29 years $\pm 8.6 \mathrm{SD}$ ) were recruited. Baseline lung function assessed by whole-body plethysmography was in the normal range for all the ubjects (Table 2). Mean PD20 was $587 \mu \mathrm{g}( \pm 535$ SD). Functional aerobic assessment $\left(\mathrm{VO}_{2} \mathrm{max}\right.$, MAP and maximum heart rate) and the mean power sustained during the exercise pharmacokinetic session are presented in

Table 2 Distribution of baseline respiratory characteristics of the subjects ( $n=12$ male participants)

\begin{tabular}{llllll}
\hline & Minimum & Median & Maximum & Mean & SD \\
\hline TLC & 99 & 115 & 133 & 116 & $12 \cdot 0$ \\
Forced vital capacity & 97 & 118 & 130 & 117 & $11 \cdot 6$ \\
FEV $_{1}$ & 93 & 110 & 125 & 110 & $9 \cdot 1$ \\
FEV $_{1} /$ FVC ratio & 75 & 78 & 92 & 79 & $6 \cdot 7$ \\
PD20; $\mu \mathrm{gg}$ & 50 & 535 & 1500 & 587 & 535 \\
\hline
\end{tabular}

Abbreviations: TLC total lung capacity, FVC forced vital capacity, $F E V_{1}$ onesecond forced expired volume, $F E V_{1} / F V C$ ratio Tiffeneau-Pinelli index. Data for TLC, FVC, $\mathrm{FEV}_{1}$ and $\mathrm{FEV}_{1} / \mathrm{FVC}$ ratio are $\%$ of the corresponding predicted value
Table 3. According to the ATS categorization of bronchial hyper-responsiveness (BHR), four participants $(33.3 \%)$ had moderate to severe BHR, two (16.7\%) had mild BHR and six (50\%) were borderline. Four subjects declared a treatment to control asthma: $10 \mathrm{mg} \cdot \mathrm{d}^{-1}$ montelukast $(n=1), 50 \mu \mathrm{g} \cdot \mathrm{d}^{-1}$ salmeterol + fluticasone $(n=1), 12 \mu \mathrm{g} \cdot \mathrm{d}^{-1}$ formoterol $(n=1)$ or $12 \mu \mathrm{g} . \mathrm{d}^{-1}$ formoterol + budenoside $(n=1)$. As required, these subjects stopped their standard treatment 2 weeks before the first pharmacokinetic session (D1).

All the subjects practiced cycling at competitive level and were well-trained endurance athletes as indicated by their $\mathrm{VO}_{2}$ max and $\mathrm{MAP} / \mathrm{kg}$ values.

\section{Urine density}

As participants were encouraged to drink water ad libitum to ensure diuresis (required for urine sampling), urine density significantly decreased from the beginning to the end of each session (Fig. 2).

\section{Salbutamol urinary concentration}

Figure $3 \mathrm{a}$ and $\mathrm{b}$ present the distribution of salbutamol concentration in urine during the rest and exercise sessions, respectively. Table 4 presents the distribution of $\mathrm{C}_{\mathrm{u}}$ max-rest, $\mathrm{C}_{\mathrm{u}}$ max-ex and $\mathrm{C}_{\mathrm{u}}$ max and their confidence interval. $\mathrm{C}_{\mathrm{u}}$ max was observed in ten participants during the exercise session and in nine after the exercise bout. The maximal concentration was measured at 2:00 pm (i.e., $4 \mathrm{~h}$ after the exercise bout). Based on the upper value of the 95 and $99 \%$ confidence intervals, the threshold value of urine salbutamol for anti-doping control could be stricter, at 327.7 and $372.4 \mathrm{ng} \cdot \mathrm{mL}^{-1}$ respectively.

\section{Discussion}

One could argue that there is no need to change the rules but rather to educate athletes, coaches and the health care providers who care about the proper use of SABAs rather than to prevent athletes from participating. However, sanction against cheaters remains a key point to fight against doping in sport and we need to improve the judgment criteria before adopting any disciplinary sanction against an athlete. By using conditions in accordance with the experts' clinical and safety guidelines for asthma management in athletes undergoing an intense exercise bout, our study demonstrates that the urine salbutamol concentration threshold could be lowered to redefine the rule supporting the decision to sanction an athlete for salbutamol abuse. Under a minimal inhaled salbutamol dose regimen, our study demonstrates that a urine salbutamol concentration threshold of $507 \mathrm{ng} \cdot \mathrm{mL}^{-1}$ could be used to redefine the rule supporting the decision to sanction an athlete for salbutamol abuse. This threshold is very far from the actual WADA threshold defined for a 
Table 3 Distribution of the results of functional aerobic assessment of the subjects ( $n=12$ male participants; $\mathrm{VO}_{2}$ max: maximal oxygen uptake; MAP: maximal aerobic power; SD: standard deviation)

\begin{tabular}{|c|c|c|c|c|c|}
\hline & Minimum & Median & Maximum & Mean & SD \\
\hline$\overline{\mathrm{VO}_{2} \mathrm{max} ; \mathrm{mL} \cdot \mathrm{min}^{-1}}$ & 2800 & 3800 & 4700 & 3858 & 340 \\
\hline $\mathrm{VO}_{2} \max ; \mathrm{mL} \cdot \mathrm{min}^{-1} \cdot \mathrm{kg}^{-1}$ & 41 & 59 & 67 & 57 & $8 \cdot 4$ \\
\hline MAP; watts & 210 & 305 & 340 & 294 & 40 \\
\hline MAP/weight; watt.kg ${ }^{-1}$ & 3.3 & 4.4 & 5.1 & 4.3 & $0 \cdot 6$ \\
\hline Maximum heart rate; beats. $\mathrm{min}^{-1}$ & 177 & 192 & 214 & 193 & $9 \cdot 9$ \\
\hline Mean power during exercise session; watts & 160 & 225 & 250 & 215 & $31 \cdot 6$ \\
\hline Mean power during exercise session; ratio to MAP \% & $62 \cdot 1$ & 74 & $81 \cdot 0$ & $73 \cdot 2$ & $5 \cdot 7$ \\
\hline
\end{tabular}

not recommended inhaled salbutamol dose. Even a "statistically" more stringent threshold could be proposed if anti-doping instances planned to consider the upper limit of the $99 \%$ confidence interval of salbutamol concentration in urine, and not the absolute maximum value detected. Our proposal to implement a new threshold is supported by methodological points supporting scientific based bases for anti-doping policy. However, this proposal is also closely related to some other methodological points that make our proposal too conservative to be applied for the heterogeneous population of asthmatic athletes.

Recently, Elers et al. highlighted methodological concerns that should be taken into account in scientific studies to support anti-doping policies against salbutamol abuse. Salbutamol dosing regimen, athletic status and testing conditions (rest/exercise) were previously shown to influence the pharmacokinetics of inhaled salbutamol [19]. This methodological concern was also stressed by the Joint Task Force of European Respiratory Society and the European Academy of Allergy and
Clinical Immunology: "Although treatment of EIB has been extensively studied in asthmatic subjects, it was not so in athletes with EIB and it is not known whether athletes with EIB respond similarly to subjects with classical allergic or nonallergic asthma" [20]. Such a methodological defect can also be highlighted in recent studies supporting the WADA restrictions to detect an abuse of inhaled formoterol according to formoterol concentration in urine [21]. Our study is the first to follow this new methodological approach as asthmatic and trained subjects were tested during a bout of intense exercise. Our study could have been done in controls subjects defined as non-asthmatic athletes to clearly identify the impact of the asthmatic status on salbutamol pharmacokinetic in urine but we were limited by organizational conditions. Elers tried to give an answer to this question after administration of a single high inhaled dose of salbutamol $(800 \mu \mathrm{g})$ [22]. However he selected nonathletic subjects as controls and despite he found no influence of asthma on urine salbutamol concentration, this question remains

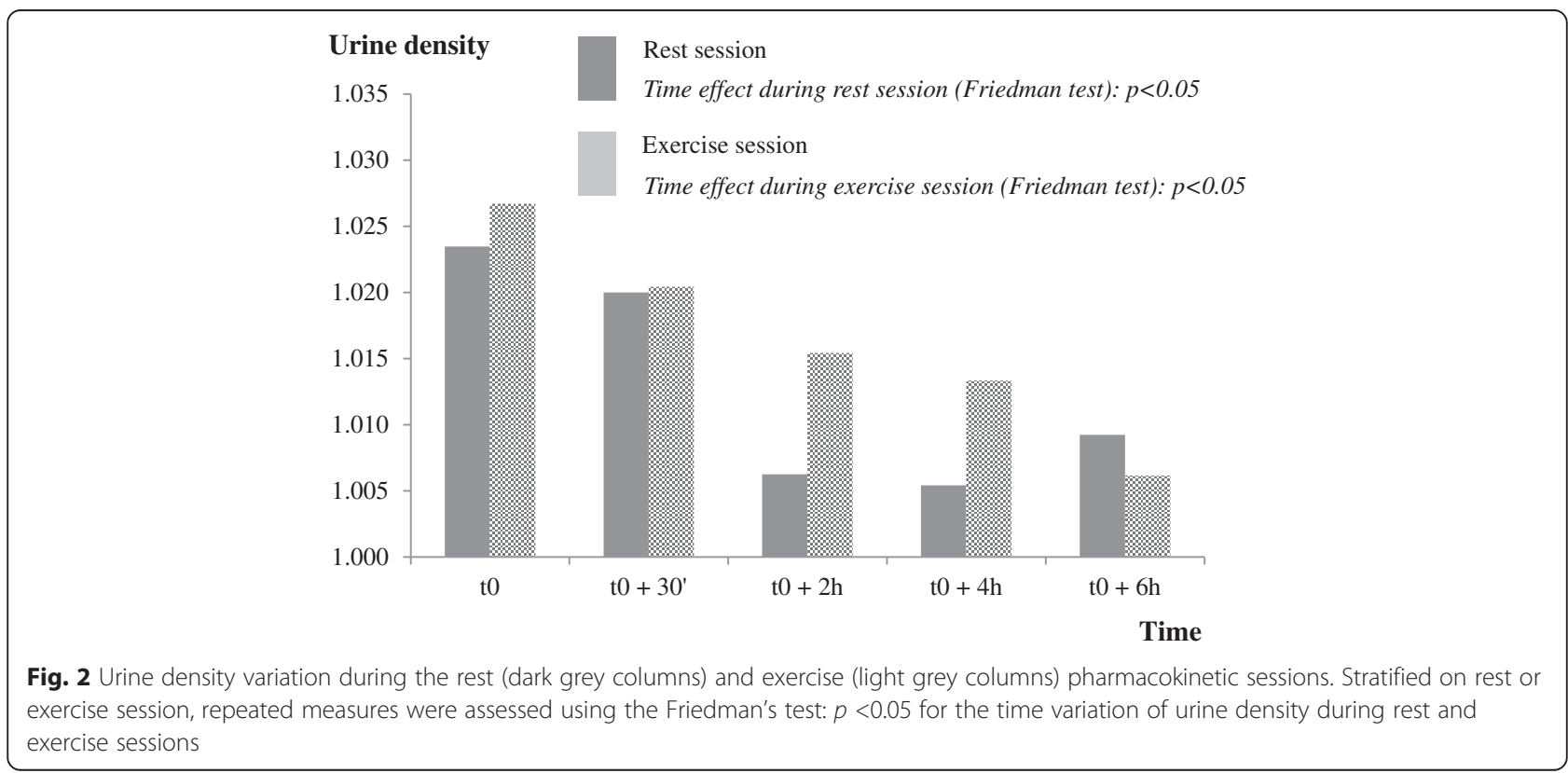



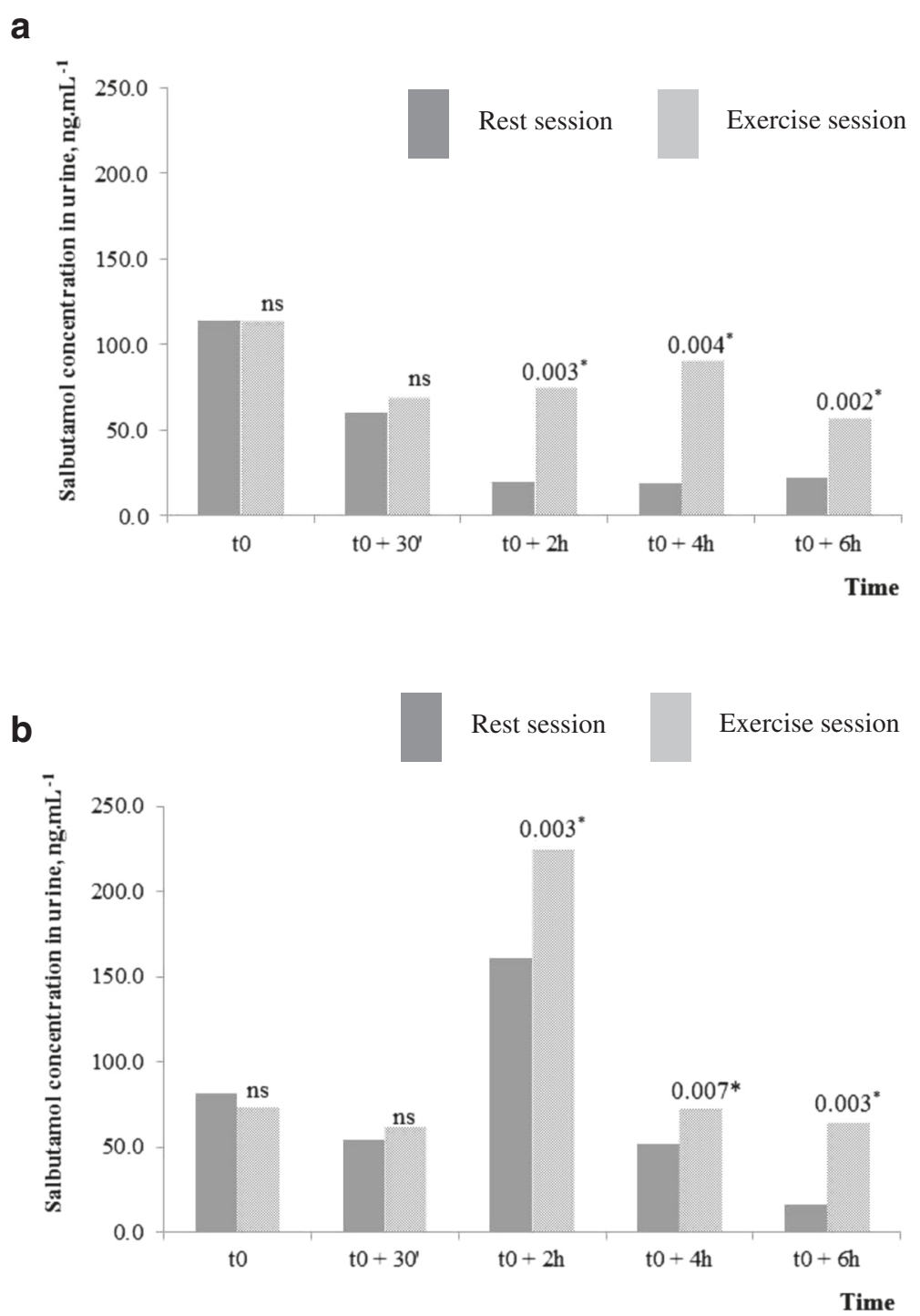

Fig. 3 a Salbutamol urine concentration (ng. $\mathrm{mL}^{-1}$ ) before (dark grey columns) and after correction (light grey columns) for urine density during the rest pharmacokinetic session. Bivariate comparisons (Wilcoxon sign rank test) between corrected and uncorrected time-stratified values. Bonferroni correction of the significance level: ${ }^{*} p<0.01$. b Salbutamol urine concentration $\left(\mathrm{ng}^{\mathrm{mL}}{ }^{-1}\right.$ ) before (dark grey columns) and after correction (light grey columns) for urine density during the exercise pharmacokinetic session. Bivariate comparisons Wilcoxon (sign rank test) between corrected and uncorrected time-stratified values. Bonferroni correction of the significance level: * $p<0.01$

unresolved to implement some scientific data that could be useful to enhance specificity of the detection of salbutamol abuse in asthmatic but also nonasthmatic athletes.

Moreover, urine density correction of urine salbutamol concentration must be considered to minimize the effect of this biological condition on the anti-doping judgment criteria [19]. While this correction was not applied to urine salbutamol concentration proposed in the article by Berges et al. [11] that was used to define the actual upper threshold in the WADA prohibition list, we considered this potent bias and we corrected the urine salbutamol concentration for urine density. This correction is of interest to take into account the state of hydration because dehydration alters the urine specific density, for example during intense and prolonged exercise, thus favoring an overestimation of urine salbutamol [9].

According to these two methodological points, our study mirror field sports practice and it could help to implement some required medical and scientific based bases for doping control management [23].

The urine concentration threshold derived from our study after a daily minimal dose of inhaled salbutamol to prevent EIB $(3 \times 200 \mu \mathrm{g})$ is twice lower than the actual threshold of $1000 \mathrm{ng} \cdot \mathrm{mL}^{-1}$ proposed in the WADA prohibited list to sanction salbutamol abuse. However, this "legal" threshold is based on pharmacokinetic data after 
Table 4 Distribution of the urine density corrected maximum urine concentration of salbutamol at rest ( $\mathrm{C}_{\mathrm{u}}$ max-rest), after the acute exercise bout ( $C_{u}$ max-ex) and regardless these specific rest or post-exercise conditions (highest of these specific values for each participant, $\mathrm{C}_{\mathrm{u}}$ max)

\begin{tabular}{llll}
\hline & $\begin{array}{l}\mathrm{C}_{\mathrm{u}} \text { max-rest } \\
n g \cdot m L^{-1}\end{array}$ & $\begin{array}{l}\mathrm{C}_{\mathrm{u}} \text { max-ex } \\
n g \cdot m L^{-1}\end{array}$ & $\begin{array}{l}\mathrm{C}_{\mathrm{u}} \max \\
\mathrm{ng} \cdot \mathrm{mL}^{-1}\end{array}$ \\
\hline Minimum & $46 \cdot 9^{*}$ & $47 \cdot 4$ & $66 \cdot 0$ \\
Median & $134 \cdot 7^{*}$ & $116 \cdot 4$ & $127 \cdot 2$ \\
Maximum & $276 \cdot 7^{*}$ & $507 \cdot 2$ & $507 \cdot 2$ \\
Mean & $144 \cdot 6$ & $208 \cdot 9$ & $218 \cdot 8$ \\
Standard deviation & $74 \cdot 7$ & $179 \cdot 4$ & $171 \cdot 3$ \\
$95 \% \mathrm{Cl}$ & $94 \cdot 4-194 \cdot 7$ & $94 \cdot 9-322 \cdot 8$ & $110 \cdot 0-327 \cdot 7$ \\
$99 \% \mathrm{Cl}$ & $73 \cdot 2-215 \cdot 6$ & $48 \cdot 1-369 \cdot 7$ & $65 \cdot 2-372 \cdot 4$ \\
\hline
\end{tabular}

$95 \% \mathrm{Cl}: 95 \%$ Confidence Interval. *Wilcoxon test between rest and exercise values: $p=0.04$

a daily dose of $1600 \mu \mathrm{g}$ inhaled salbutamol, i.e. 8 fold the total dose sequentially administrated in our study. Despite regular daily chronic use of salbutamol as a controller is not recommended by current guidelines, we justify the three times daily inhalation of salbutamol scheduled for the present study to prevent asthma symptoms in the four patients who declared a daily treatment to control asthma. These patients were asked to abstain from using this treatment 2 weeks before the pharmacokinetic session to avoid a potent influence of such treatments on salbutamol kinetic, as previously suggested for inhaled corticosteroids for example [24]. The dosing regimen was justified to ensure homogeneity of the pharmacological condition proposed in all volunteers. After such a preliminary study, we highlight that influence of a treatment to control asthma on inhaled salbutamol kinetic in exercise condition and in asthmatic athletes would be of interest to optimize sensitivity and specificity of salbutamol abuse detection in sport field conditions.

At the present time, experts' guidelines for EIB do not explicitly state an optimal or minimal dose of salbutamol but ATS EIB guidelines do cite a reference which states that a patient should be instructed to use two $(200 \mu \mathrm{g})$ to four $(400 \mu \mathrm{g})$ puffs of an inhaled SABA 30 to $60 \mathrm{~min}$ before exercise [7]. Thus, considering that more severe asthmatics undergoing very intense exercise for prolonged periods might require additional doses of salbutamol (i.e. 4 total puffs, $400 \mu \mathrm{g}$ ) before exercise, we are aware that our pharmacokinetic data on salbutamol urine concentration are conservative for implementation as a threshold for anti-doping legacy. After 400 ug inhaled salbutamol, the resulting salbutamol urine concentration could have been higher than the $\mathrm{C}_{\mathrm{u}}$ max reported in our study. However, we can argue that we selected the lowest dose recommended by experts in respect to the corresponding asthma severity of the patients from our study. Moreover, even if we had considered the highest dose proposed by clinical experts $(400 \mu \mathrm{g})$, this dose would have been very far from the maximal inhaled dose of salbutamol authorized by the WADA list $(1600 \mu \mathrm{g})$ and our clinical based approach questions about ethical and medical safety of the very high dose of inhaled salbutamol authorized by WADA. Indeed, we kept in mind that regular use of BAs can lead quickly to tolerance (tachyphylaxis), reduction of their bronchoprotective effect $[2,20]$ and that high metrics of salbutamol use are supposed to be good markers of current asthma control, risk of future severe exacerbations and increased risk of future extreme salbutamol overuse [25]. We could have evaluated the beneficial and adverse effects of the daily regular minimal dose of salbutamol inhaled but the design of our study did not evaluate these effects of salbutamol use as a basis for determining a threshold to detect inhaled salbutamol abuse. Thus, one being not able to exclude that adverse effects associated with high inhaled dose of salbutamol are related to either more severe asthma or an adverse response to SABA, we questioned about ethical and medical safety of a very high inhaled salbutamol dose (like $1600 \mu \mathrm{g} . \mathrm{j}^{-1}$ ) as a treatment scheme in athlete while the athlete is exposed to hyperventilation during intense and prolonged exercise, a potent condition for asthma occurrence. Sports practice should not be exempted from avoiding common factors associated with asthma exacerbation, such as allergens and pollutants for allergic asthma, but also hyperventilation of cold and dry air for EIB, especially when high dose of inhaled salbutamol could be "required". This assertion could prevent athletes to inhale high doses of salbutamol, not "inadvertently" for doping, but "intentionally" in respect to the safety of medical and environmental considerations. However, in the case of asthma crisis, a high dose of salbutamol could be inhaled by athletes in a day, up to $1600 \mu \mathrm{g}$ as authorized by WADA. If the crisis occurs out of competition, this high dose might be acceptable because it could be associated with the control of the environmental conditions, particularly avoidance of ventilatory conditions that triggers EIB. Under this medical consideration, we suggest to consider that anti-doping legacy to detect salbutamol abuse could be based on two salbutamol urine concentration, one that could apply out of competition (a high dose of inhaled salbutamol could be authorized) and one that could apply during a competition (a high dose of inhaled salbutamol wouldn't be authorized).

A last point supporting the conservative aspect of our study is related to the methodological choice that limited the study to men. This choice was due to multiple pharmacological variations in women related to menstrual cycle. Like us, most of the previous studies to assess the pharmacokinetic of salbutamol were selectively 
conducted only in men. The study supporting the actual WADA urine salbutamol concentration threshold is one of these studies. Thus, future studies should target a female cohort of asthmatic athletes to implement the results to all asthmatic athletes.

\section{Conclusion}

Based on medical considerations and methodological concerns, our study provides some evidence about the need to revise the actual WADA maximum inhaled salbutamol dose authorized and the urine salbutamol concentration threshold used to detect and sanction salbutamol abuse in athletes. Our revised urine salbutamol concentration threshold is based on medical evidence on the recommended daily inhaled dose of salbutamol and dosing regimens. In the case of an asthma attack or in the presence of recurrent symptoms, the dose of inhaled salbutamol could be increased but we argue that athletes should also be excluded from risky situations for EIB, like hyperventilation that is common during competition. Accordingly, we propose to consider that further studies should be planned to define the upper confident threshold of salbutamol concentration in urine in asthmatic athletes, in competition and out of competition, after inhalation of an upper limitlow dose $(400 \mu \mathrm{g})$ or a high dose $(1600 \mu \mathrm{g})$ salbutamol. Notwithstanding the pharmacokinetic dimension of the problem, WADA prohibited list should also base the recommendations on the maximum daily dose of inhaled salbutamol on best practice approaches for asthma management.

\begin{abstract}
Abbreviations
WADA: World Anti-Doping Agency; IOC: International Olympic Committee; EIB: Exercise induced bronchospasm; ATS: American Thoracic Society; BA: beta2-agonist; SABA: Short-acting beta2-agonist; GINA: Global Initiative for Asthma; COPD: Chronic obstructive pulmonary disease; APS: Aerosol Provocation System; FEV1: Forced expiratory volume in 1 second; PD20: Provocative dose $20 \%, \mu \mathrm{g} ; \mathrm{VO}_{2}$ : Oxygen consumption debt, L. $\mathrm{min}^{-1}$; MAP: Maximal aerobic power, watt; BHR: Bronchial hyper-responsiveness.
\end{abstract}

\section{Competing interests}

All authors disclose professional relationship with companies or manufacturers who would benefit from the results of the present study.

\section{Authors' contribution}

FP (lead author): conceptualized and designed the study, carried out the laboratory exercise testing sessions (maximal exercise testing on treadmill coupled with gas exchange assessment), carried out the biological material collection, carried out the data collection, carried out the statistical analysis, drafted the initial manuscript and approved the final manuscript as submitted. ML (contributor): carried out the biological analytical process of the study, critically reviewed the manuscript and approved the final manuscript as submitted. VL-C (contributor): conceptualized the statistical part of the method, carried out the statistical analysis, critically reviewed the manuscript and approved the final manuscript as submitted. JR (contributor): conceptualized and designed the study, carried out the biological material collection, critically reviewed the manuscript and approved the final manuscript as submitted. GH (contributor): critically reviewed the manuscript and approved the final manuscript as submitted. AD (contributor): critically reviewed the manuscript and approved the final manuscript as submitted. DR (contributor): conceptualized and designed the study, critically reviewed the manuscript and approved the final manuscript as submitted. All authors read and approved the final manuscript.

\section{Acknowledgements}

The study was supported and granted by the Agence Française de Lutte contre le Dopage (French Anti-Doping Agency). The authors would like to acknowledge Elisabetta Andermarcher for her support in reviewing the article.

\section{Author details}

${ }^{1}$ Respiratory Function Exploration and Sport Medicine Department, Larrey Hospital, 24 Chemin de Pouvourville, TSA 30030, 31059 Toulouse Cedex 9, France. ${ }^{2}$ Exercise Physiology Department, Medical School, Paul Sabatier University, Toulouse, France. ${ }^{3}$ INSERM, U858-Adipolab Unit, Institute of Molecular Medicine, Toulouse, France. ${ }^{4}$ Pharmacokinetic and Toxicologic Laboratory, Institute of Biology, Purpan Hospital, Toulouse, France. ${ }^{5}$ Epidemiology Department, Medical School, Paul Sabatier University, Toulouse, France. ${ }^{6}$ Department of Respiratory Diseases, Larrey Hospital, Toulouse, France.

Received: 14 August 2015 Accepted: 15 December 2015

Published online: 24 December 2015

\section{References}

1. Final revised 2015 World Anti-Doping Code and Prohibited list. 2015. at www.wada-ama.org. Accessed date: 23 December 2015.

2. Fitch KD, Sue-Chu M, Anderson SD, Boulet LP, Hancox RJ, McKenzie DC, et al. Asthma and the elite athlete: summary of the International Olympic Committee's consensus conference, Lausanne, Switzerland, January 22-24, 2008. J Allergy Clin Immunol. 2008;122:254-60. 60.e1-7.

3. Hostrup M, Kalsen A, Auchenberg M, Bangsbo J, Backer V. Effects of acute and 2-week administration of oral salbutamol on exercise performance and muscle strength in athletes. Scand J Med Sci Sports. 2014.

4. Pluim BM, de Hon O, Staal JB, Limpens J, Kuipers H, Overbeek SE, et al. beta(2)-Agonists and physical performance: a systematic review and metaanalysis of randomized controlled trials. Sports Med. 2011;41:39-57.

5. Global INitiative for Asthma. Pocket guide for asthma management and prevention (for adults and children over than 5 years): Global INitiative for Asthma. 2014

6. Parsons JP, Hallstrand TS, Mastronarde JG, Kaminski D, Rundell K, Hull J, et al. An official American Thoracic Society clinical practice guideline: exerciseinduced bronchoconstriction. Am J Respir Crit Care Med. 2013;187:1016-27.

7. Tan RA, Spector SL. Exercise-induced asthma: diagnosis and management. Ann Allergy Asthma Immunol. 2002;89:226-35. quiz 35-7, 97.

8. Kippelen P, Anderson SD. Pathogenesis of exercise-induced bronchoconstriction. Immunol Allergy Clin N Am. 2013;33:299-312. vii.

9. Dickinson J, Hu J, Chester N, Loosemore M, Whyte G. Impact of ethnicity, gender, and dehydration on the urinary excretion of inhaled salbutamol with respect to doping control. Clin J Sport Med. 2014.

10. Boulet LP, O'Byrne PM. Asthma and exercise-induced bronchoconstriction in athletes. N Engl J Med. 2015:372:641-8.

11. Berges R, Segura J, Ventura R, Fitch K, Morton A, Farre M, et al. Discrimination of prohibited oral use of salbutamol from authorized inhaled asthma treatment. Clin Chem. 2000;46:1365-75.

12. Crapo $R O$, Casaburi $R$, Coates $A L$, Enright $P L$, Hankinson $J$, Irvin $C G$, et al. Guidelines for methacholine and exercise challenge testing-1999. This official statement of the American Thoracic Society was adopted by the ATS Board of Directors, July 1999. Am J Respir Crit Care Med. 2000;161:309-29.

13. Schulze J, Rosewich M, Riemer C, Dressler M, Rose MA, Zielen S. Methacholine challenge-comparison of an ATS protocol to a new rapid single concentration technique. Respir Med. 2009;103:1898-903.

14. Bertucci W, Duc S, Villerius V, Pernin JN, Grappe F. Validity and reliability of the PowerTap mobile cycling powermeter when compared with the SRM Device. Int J Sports Med. 2005;26:868-73.

15. Mareck U, Guddat S, Schwenke A, Beuck S, Geyer H, Flenker U, et al. Determination of salbutamol and salbutamol glucuronide in human urine by means of liquid chromatography-tandem mass spectrometry. Drug Test Anal. 2011;3:820-7.

16. Tomlinson HS, Corlett SA, Allen MB, Chrystyn H. Assessment of different methods of inhalation from salbutamol metered dose inhalers by urinary drug excretion and methacholine challenge. Br J Clin Pharmacol. 2005;60:605-10.

17. Gardner MJ, Altman DG. Confidence intervals rather than $P$ values: estimation rather than hypothesis testing. Br Med J (Clin Res Ed). 1986;292:746-50.

18. International F. International Federation of Clinical Chemistry, Scientific Committee, Clinical Section. Expert Panel on Theory of Reference Values 
(EPTRV). The theory of reference values. Part 5. Statistical treatment of collected reference values. Determination of reference limits. Clin Chim Acta. 1984;137:97f-114.

19. Elers J, Pedersen L, Henninge J, Hemmersbach P, Dalhoff K, Backer V. The pharmacokinetic profile of inhaled and oral salbutamol in elite athletes with asthma and nonasthmatic subjects. Clin J Sport Med. 2012;22:140-5.

20. Carlsen KH, Anderson SD, Bjermer L, Bonini S, Brusasco V, Canonica W, et al. Treatment of exercise-induced asthma, respiratory and allergic disorders in sports and the relationship to doping: Part II of the report from the Joint Task Force of European Respiratory Society (ERS) and European Academy of Allergy and Clinical Immunology (EAACl) in cooperation with GA(2)LEN. Allergy. 2008;63:492-505

21. Eibye K, Elers J, Pedersen L, Henninge J, Hemmersbach P, Dalhoff K, et al. Formoterol concentrations in blood and urine: the World Anti-Doping Agency 2012 regulations. Med Sci Sports Exerc. 2013:45:16-22.

22. Elers J, Morkeberg J, Jansen T, Belhage B, Backer V. High-dose inhaled salbutamol has no acute effects on aerobic capacity or oxygen uptake kinetics in healthy trained men. Scand J Med Sci Sports. 2012;22:232-9.

23. No author listed. A level playing field? Nature 2008;454:667.

24. Naidu Sjosward K, Josefsson M, Ahlner J, Andersson RG, Schmekel B. Metabolism of salbutamol differs between asthmatic patients and healthy volunteers. Pharmacol Toxicol. 2003:92:27-32.

25. Patel M, Pilcher J, Reddel HK, Pritchard A, Corin A, Helm C, et al. Metrics of salbutamol use as predictors of future adverse outcomes in asthma. Clin Exp Allergy. 2013;43:1144-51.

26. Anderson PJ, Zhou X, Breen P, Gann L, Logsdon TW, Compadre CM, et al. Pharmacokinetics of (R, S)-Albuterol after aerosol inhalation in healthy adult volunteers. J Pharm Sci. 1998;87:841-4.

27. Pichon A, Venisse N, Krupka E, Perault-Pochat MC, Denjean A. Urinary and blood concentrations of beta2-agonists in trained subjects: comparison between routes of use. Int I Sports Med. 2006;27:187-92.

28. Sporer BC, Sheel AW, McKenzie DC. Dose response of inhaled salbutamol on exercise performance and urine concentrations. Med Sci Sports Exerc. 2008:40:149-57.

29. Sporer BC, Sheel AW, Taunton J, Rupert JL, McKenzie DC. Inhaled salbutamol and doping control: effects of dose on urine concentrations. Clin J Sport Med. 2008;18:282-5.

30. Elers J, Pedersen L, Henninge J, Lund TK, Hemmersbach P, Dalhoff K, et al. Blood and urinary concentrations of salbutamol in asthmatic subjects. Med Sci Sports Exerc. 2010;42:244-9.

31. Elers J, Pedersen L, Henninge J, Hemmersbach P, Dalhoff K, Backer V. Urine concentrations of repetitive doses of inhaled salbutamol. Int I Sports Med. 2011:32:574-9.

\section{Submit your next manuscript to BioMed Central and we will help you at every step:}

- We accept pre-submission inquiries

- Our selector tool helps you to find the most relevant journal

- We provide round the clock customer support

- Convenient online submission

- Thorough peer review

- Inclusion in PubMed and all major indexing services

- Maximum visibility for your research

Submit your manuscript at www.biomedcentral.com/submit

) Biomed Central 